\title{
Kidney Function Test of Female Wistar Rat (Rattus norvegicus Berkenhout, 1769) of Subchronic Toxicity Test of Arthrospira maxima and Chlorella vulgaris
}

\author{
Mulyati $^{1 *}$, Anita Yuliana ${ }^{1}$, Slamet Widiyanto ${ }^{1}$ \\ 1) Faculty of Biology, Universitas Gadjah Mada, Jl. Teknika Selatan, Sekip Utara, Yogyakarta, 55128 \\ Corresponding author, telp.: 08122766569, email address : mulyati.biougm@ugm.ac.id
}

\section{Keywords: \\ A. maxima \\ C. vulgaris \\ creatinine \\ urea}

kidney index

glomerular structure

\section{Article history:}

Submitted 31/12/2018

Revised 11/11/2019

Accepted 22/11/2019

\begin{abstract}
Arthrospira maxima and Chlorella vulgaris are contained a high protein and antioxidant levels that can be used as functional foods or supplements to improve health. Furthermore, this material needs to be monitored for safety. The aims of this research were determined the subchronic toxicity test of microalgae A. maxima and C. vulgaris on kidney function. Parameters of this research were creatinine levels, urea levels, kidney index, and histological structure of the kidney glomerular. Besides that, the progression of body weight was observed. Five teen female Wistar rats (Rattus norvegicus Berkenhout,1769) divided into three groups randomly were one control group and two treatment groups using A. maxima and C. vulgaris in the same dose were $2500 \mathrm{mg} / \mathrm{kg}$ of body weight. Subchronic toxicity test was conducted by oral gavage every day during 90 days - the measurement of creatinine levels and urea levels on the $30^{\text {th }}, 60^{\text {th }}$, and $90^{\text {th }}$ day. Kidney index and glomerular histology of rat's kidney was prepared after necropsy at the end of this research. Base on the results, it can be concluded that consume of Arthrospira maxima, and Chlorella vulgaris at $2500 \mathrm{mg} / \mathrm{kg}$ of body weight increased creatinine and urea levels. Bodyweight, kidney index, and pathological glomerular cells of histological kidney were still in normal value.
\end{abstract}

\section{INTRODUCTION}

Microalgae are micro-sized algae groups. It has many types, which are commonly found in marine and freshwater with sizes ranging from a few micrometers to several hundred micrometers. Microalgae are a source of nutrition that provides several bioactive compounds, polymers, peptides, fatty acids, carotenoids, sterols, and toxins (Kim, 2015).

Microalgae have been investigated as a food or nutrition source for humans and animals for more than six decades (Liu et al., 2014). Two species of microalgae that can be used as functional foods and are the focus of this study are Arthrospira maxima and Chlorella vulgaris. Over the past 2-3 decades, millions of people around the world have consumed $A$. maxima as a food supplement. A. maxima is also rich in vitamin B12, carotene, omega-3 and omega- 6 as essential fatty acids and antioxidants, which are very beneficial for the health of the body (Affan et al., 2015). Chlorella vulgaris also has high protein content, rich in vitamins, minerals, omega-3 fatty acids, and carotenoids (Gouveia et al., 1995).

In the body of $A$. maxima and $C$. vulgaris will be digested, absorbed, and distributed through the blood circulation. Afterwards, follow the metabolic process in the liver and then the soluble elements in the water will be excreted through the kidneys. Therefore, it is necessary to monitor the safety of $A$. maxima and C. vulgaris as functional foods through subchronic oral toxicity studies. The effects of microalgae $A$. maxima and $C$. vulgaris on kidney function was evaluated. Bodyweight, kidney index, creatinine level, urea level, and glomerular structure were chosen to evaluate the kidney function. 


\section{MATERIALS AND METHODS}

\section{Materials}

This research was conducted from October 2017 to March 2018. Orally sub-chronic toxicity test and measuring of creatinine and urea level was conducted at the Integrated Laboratory Research and Testing (Laboratorium Penelitian dan Pengujian Terpadu, LPPT) UGM. Preparation of kidney using paraffin method was done at the Laboratory of Animal Structure and Development of the Faculty of Biology UGM. This experiment was done after obtaining approval from the Animal Ethics Commission Team with certificate number 00096/04/LPPT/VII/2017. The material used in this research was Arthrospira maxima, and Chlorella vulgaris powder was obtained from Blue Green Alga (BGA) Biotechnology, female Wistar rat (Rattus norvegicus Berkenhout 1769) 2 months. The chemicals needed in the process of histology preparations are distilled water, NBF (Neutral Buffered Formalin), alcohol, toluol, enthelan, paraffin, paraffin I, II, and III, xylol, Meyer`s albumin, Erlich Hematoxylin, and Eosin-Y 1-2\%.

\section{Methods}

\section{Subchronic orally toxicity test}

Before done the treatment, rats acclimated for five days. Giving feed and drinking Reverse Osmosis water ad libitum. Fifteen rats divided into three groups and treated microalgae of $2500 \mathrm{mg} / \mathrm{kg}$ of body weight in dose, five rats treated with $A$. maxima, five rats treated with $C$. vulgaris, and five rats for control with force-fed distilled water as much as $2 \mathrm{~mL}$.

\section{Blood Chemistry Analysis}

The blood sample was collected through the orbital sinus after anesthetist with ketamine on the day of 30 (D-30), 60 (D-60), and 90 (D-90) respectively. The creatinine and urea level was measured with the colorimetric method using a spectrophotometer, conducted at LPPT UGM.

\section{Preparation of Glomerular Kidney Histology}

The kidney organ was fixed in Neutral Buffered Formalin (NBF) solution for 48 hours. Washing with $70 \%$ alcohol, then dehydration using graded alcohol from a concentration of $70 \%, 80 \%, 90 \%$, $96 \%$, and absolute respectively. The clearing was carried out using toluol overnight. Paraffin infiltration was done in the oven at $60 \square \mathrm{C}$. Embedding part of kidney tissue to form paraffin blocks. After that, was done trimming on the paraffin blocks and sectioning with a thickness of 5 $\mu \mathrm{m}$. Furthermore, the affixing of these coups $(+$ kidney tissue) was carried out on objects glass and then staining with Hematoxylin-Eosin (HE). Object glass with kidney histological was labelled, observed, and analyzed. The disturbing of cells function or pathological cells state be assessed by determining and calculating of each cell state for all the cells in histological glomerular.

Data of body weight, kidney index, urea level, and creatinine level for evaluating kidney function test tabulated in Microsoft Excel 2016 software. The data were statistically analyzed using one-way $A N O V A$ with a $95 \%$ confidence level. If there is a difference, then followed by Duncan's Multiple Range Test (DMRT) using a software program (software) SPSS 23. Glomerular structure and pathological cells state were observed descriptively.

\section{RESULTS AND DISCUSSION}

\section{Body Weight}

In this study, weighing the bodyweight of the animals model was done once a week to observe the effect of the administration of $A$. maxima and $C$. vulgaris on animals model body weight. Data body weight development of female Wistar rats for 90 days be shown in Figure 1 and Table 1.

Table 1. Progression of body weight from female Wistar rats (Rattus norvegicus, Berkenhout1769) with A. maxima and $C$. vulgaris treatment in subchronic orally toxicity test

\begin{tabular}{ll}
\hline Group & Rats obtained weight (grams) \\
\hline Control & $77.26 \pm 21.42^{\text {a }}$ \\
Arthrospira maxima & $77.58 \pm 8.72^{\text {a }}$ \\
Chlorella vulgaris & $78.06 \pm 10.92^{\text {a }}$ \\
\hline
\end{tabular}

Based on Figure 1, it can be seen that both control group rats and oral treatment of microalgae A. maxima and C. vulgaris $2500 \mathrm{mg} / \mathrm{kg}$ of body weight for 90 days were obtained the increasing of the body weight. The increasing of the body weight, from the highest to the lowest were treated by $C$. vulgaris $>$ A. maxima $>$ control, respectively. The progression of body weight during the treatment (after and before treatment) was presented in Table 1.

In Table 1, it is known that there was no significant difference in the increase of body weight between each group of rats. This increase in body weight is due to the increasing age and the growing of that animal experiment. This is also supported by feeding and drinking ad libitum.

Kidney Index

Kidney index was calculated at the end of this 


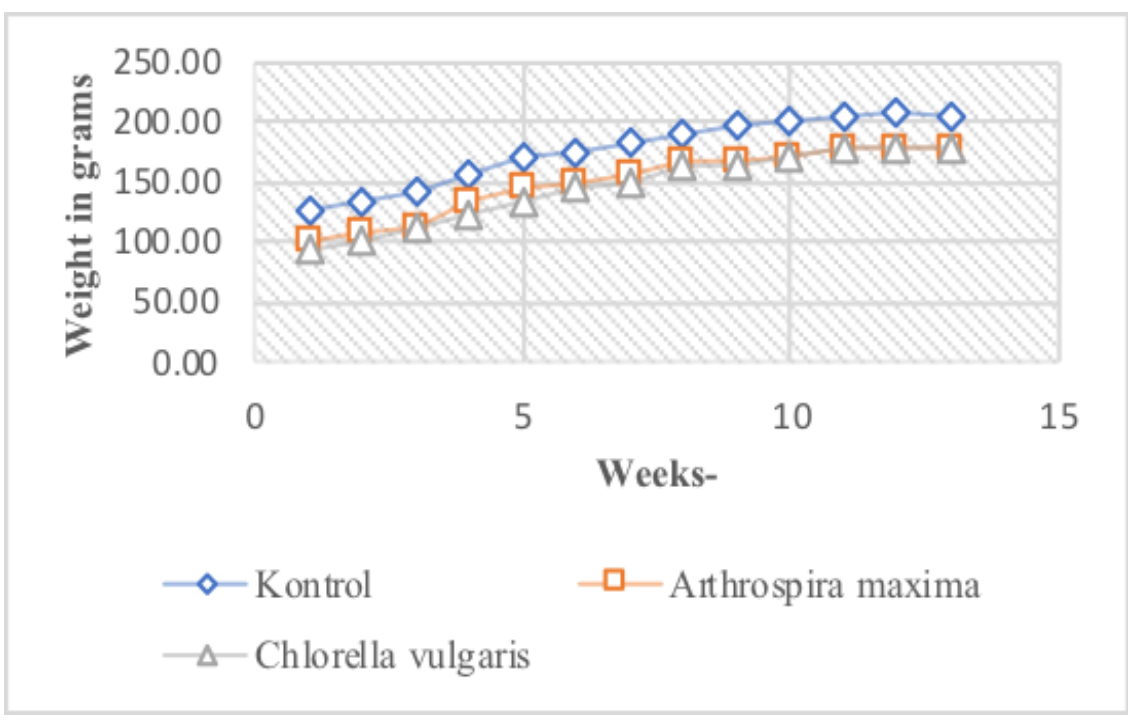

Figure 1. Bodyweight of female Wistar rats (Rattus norvegicus, Berkenhout 1769) with A. maxima and C. vulgaris treatment in a subchronic oral toxicity test

research from the kidney weight and body weight. Kidney index is one of the kinds of organ index that is to observe the condition of the organs in the body. Kidney index of this research is displayed in Table 2 underneath.

Based on Table 2, the results of statistical tests on kidney index of all groups were not significantly different. Due to it can be seen that there is no change in kidney organ mass. This result showed that the rat was given microalgae $A$. maxima and $C$. vulgaris not giving adverse effect on the kidney index so that the kidney can be function normally.

Table 2. Kidney Index of female rats (Rattus norvegicus, Berkenhout 1769) Wistar strain with A.maxima and $C$. vulgaris treatment in subchronic orally toxicity test

\begin{tabular}{ll}
\hline Group & Kidney Index \\
\hline Control & $0.9970 \pm 0.07 \mathrm{a}$ \\
Arthrospira maxima & $0.9968 \pm 0.07 \mathrm{a}$ \\
Chlorella vulgaris & $0.9969 \pm 0.10^{\mathrm{a}}$ \\
\hline
\end{tabular}

\section{Creatinine Level}

Creatinine level in blood was indicated of kidney function in the body. Creatinine is nitrogen waste products from the catabolism of creatine phosphate and muscle activity (contraction and relaxation), so increasing of creatinine level significantly in the blood is indicate there is a disorder of renal function or increasing activity of skeletal muscle. Normally, the value of rats creatinine levels according to Giknis and Clifford (2008) is $0.2-0.6 \mathrm{mg} / \mathrm{dL}$. Increasing creatinine levels in control, treated $A$. maxima, and C. vulgaris on $90^{\text {th }}$ days is still in the normal range according to previous research (Giknis and Clifford, 2008). This result has shown that no impairment of kidney functions in creatinine excretion from the body. Table 3 were presented the result of this research.

According to the Table 3 on the $30^{\text {th }}$ day, the creatinine levels of the control group rats showed significant differences with the two treatment groups, this was because the weight in normal rat was higher than the two treatments. According to Perrone et al. (1992), the other factors that influence creatinine level in the blood is muscle mass. If seen in the control group, it is reviewed based on time on the $30^{\text {th }}, 60^{\text {th }}$ and $90^{\text {th }}$ days there is not significantly different. Whereas in the treatment groups the administration of $A$. maxima and $C$. vulgaris, there were significant differences on the $60^{\text {th }}$ and $90^{\text {th }}$ day. This is due to the increase in muscle mass and weight due to the growth of the rat treated groups. The increase in creatinine levels in the treated rat can also be due to other functions of these two microalgae as antidepressant substances so that stress due to stress treatment can be reduced and does not disturb with body activity. So that increased body activity raises muscle activity which also increases creatinine levels as well. On days $30^{\text {th }}, 60^{\text {th }}$, and $90^{\text {th }}$ creatinine levels between groups did not significantly different. So $A$. maxima and $C$. vulgaris dose $2500 \mathrm{mg} / \mathrm{kg}$ could increase the creatinine levels but does not cause toxic effects because the value does not exceed the reference range of normal creatinine levels in the rat.

\section{Urea Level}

In blood, urea level was measured to assess the kidney function of the body. Urea is the excrete from the catabolism of the amino acid as endproduct of protein catabolism. So, the level of Urea in the blood can be used to diagnosis for support of kidney function. 
Table 3. Creatinine levels of female Wistar rats (Rattus norvegicus, Berkenhout 1769) with A. maxima and C.vulgaris treatment in subchronic orally toxicity test

\begin{tabular}{lccc}
\hline \multirow{2}{*}{ Group } & \multicolumn{3}{c}{ Creatinine levels in $\mathbf{~ g} / \mathbf{d L}$} \\
\cline { 2 - 4 } & H-30 & H-60 & H-90 \\
\hline Control & $0.42 \pm 0.03 \mathrm{bx}$ & $0.46 \pm 0.03$ ax & $0.50 \pm 0.05^{\mathrm{ax}}$ \\
Arthrospira maxima & $0.36 \pm 0.05^{\mathrm{ax}}$ & $0.43 \pm 0.07 \mathrm{axy}$ & $0.51 \pm 0.07_{\mathrm{ay}}$ \\
Chlorella vulgaris & $0.33 \pm 0.06^{\mathrm{ax}}$ & $0.47 \pm 0.04$ ay & $0.45 \pm 0.11^{\mathrm{ay}}$ \\
\hline
\end{tabular}

Noted in value a,b,c were compared among in the column $\mathrm{x}, \mathrm{y}$ noted were compared value among in line

Ureum levels of the group that given C. vulgaris are increased from the $30^{\text {th }}$ to the $90^{\text {th }}$ day. While the control and treatment of $A$. maxima increased on the $60^{\text {th }}$ day and decreased on the $90^{\text {th }}$ day. The Urea level from this research was presented in Table 4.

According to Table 4. can be seen on the $30^{\text {th }}$ day after the administration of treatment there was a significant difference between the control group and the administration of microalgae groups A. maxima and $C$. vulgaris. However, on the $60^{\text {th }}$ and $90^{\text {th }}$ days, there were no significant differences between each group. The high protein content in both microalgae caused an increase in ureum levels in the treatment of microalgae A. maxima and C.vulgaris. According to Verdiansah (2016), urea is the end product of protein and amino acid catabolism, produced by the liver and distributed through the blood circulation for filtration by kidney especially in the glomerulus. So high protein levels can cause high urea levels. According to Andrade and Costa (2007), A. maxima contains up to $50-70 \%$ protein of the dry weight. Similarly, Chlorella vulgaris which has a high protein content, total protein in C. vulgaris reach $55-67 \%$ from dry biomass (Safi et al., 2014). However, the following month, the rat was able to adapt well so there is no significant difference in urea levels.

If reviewed based on time differences, there will be no change significant urea levels in all three groups on $0,30^{\text {th }}, 60^{\text {th }}$, and $90^{\text {th }}$ day. This shows that the consumption of microalgae $A$. maxima and $C$. vulgaris does not cause changes in the urea significant. Thing presumably, protein levels in microalgae A. maxima and $C$. vulgaris can be obtained metabolized properly by the body of the test rat. Thus, giving microalgae A. maxima and C. vulgaris is not toxic to blood urea levels.

\section{Glomerular Kidney Histology}

The kidneys are one of the body's vital organs that regulate the metabolic process and excretion of various substances from the body in the form of urine. Glomerular is the part of the kidney that the site of the important process for waste in the blood. This research was focused on the glomerular histological structure which plays an important role in the filtration process. The glomerular structure was shown in Figure 2.

The result of the control group it can be observed that there is a pyknotic cell nucleus of $0.35 \%$ and a karyorrhexis cell nucleus of $0.35 \%$ in cells found in the glomerulus. In the treatment group $A$. maxima there was observed damage in the form of a pyknotic nucleus of $1.39 \%$, a karyorrhexis nucleus of $0.88 \%$, and vacuolization of $1.41 \%$. In the treatment group, C. vulgaris can be observed damage in the form of picnotic nucleus of $1.80 \%$, karyorrhexis cell nucleus of $0.52 \%$, and vacuolization of $1.52 \%$.

Histological observations of the presence of pyknotic, karyorrhexis, and vacuolization in the treatment group were still within normal limits with a low percentage. This can be due to $C$. vulgaris and A. maxima which function as antioxidants. C. vulgaris as an antioxidant can be used to prevent kidney damage, as in previous studies conducted by Susatyo et al. (2018) that C. vulgaris extract can reduce kidney damage exposed to $\mathrm{CCl}$. The ability of $C$. vulgaris extract provides protection against oxidative stress and free radicals associated with antioxidant compounds in it. Some antioxidants in C. vulgaris extract are lutein, a-carotene, b-carotene, ascorbic acid, chlorophyll, and tocopherol. Antioxidants that have the most important role in preventing damage from free radicals are carotene. This compound can remove a single oxygen and peroxide compound through a redox reaction.

A. maxima contain phycocyanin which functions antioxidants to prevent damage caused by free radicals. Phycocyanin is also useful in the renoprotective. A. maxima also contain beta carotene which also functions as a lipophilic antioxidant. $A$. maxima contain beta carotene around 700-1700 mg/ $\mathrm{kg}$. Overdose is unlikely to occur because betacarotene is not toxic cumulatively and bioavailability have been verified in preclinical and clinical studies. Carotenoids are the second most important pigment group found in algae (Zakaria et al., 2016). Damage due to treatment $A$. maxima and $C$. vulgaris at a dose of $2500 \mathrm{mg} / \mathrm{kg}$ of body weight for 90 days has not caused damage to the glomerular structure. 
Table 4. Urea level of female rats (Rattus norvegicus, Berkenhout 1769) Wistar strain with A. maxima and C. vulgaris treatment in subchronic orally toxicity test

\begin{tabular}{lccc}
\hline \multirow{2}{*}{ Groups } & H-30 & Urea levels in $\mathbf{~ m g} / \mathbf{d L}$ & H-90 \\
\hline Control & $34.36 \pm 2.35^{\mathrm{ax}}$ & $42.74 \pm 9.70^{\mathrm{ax}}$ & $38.92 \pm 5.30^{\mathrm{ax}}$ \\
Arthrospira maxima & $40.20 \pm 5.97 \mathrm{abx}$ & $40.60 \pm 6.86^{\mathrm{ax}}$ & $37.08 \pm 4.80^{\mathrm{ax}}$ \\
Chlorella vulgaris & $42.06 \pm 6.08^{\mathrm{bx}}$ & $42.12 \pm 4.75^{\mathrm{ax}}$ & $43.68 \pm 7.31^{\mathrm{ax}}$ \\
\hline
\end{tabular}

Noted in value a,b,c were compared among in the column $\mathrm{x}, \mathrm{y}$ noted were compared value among in line
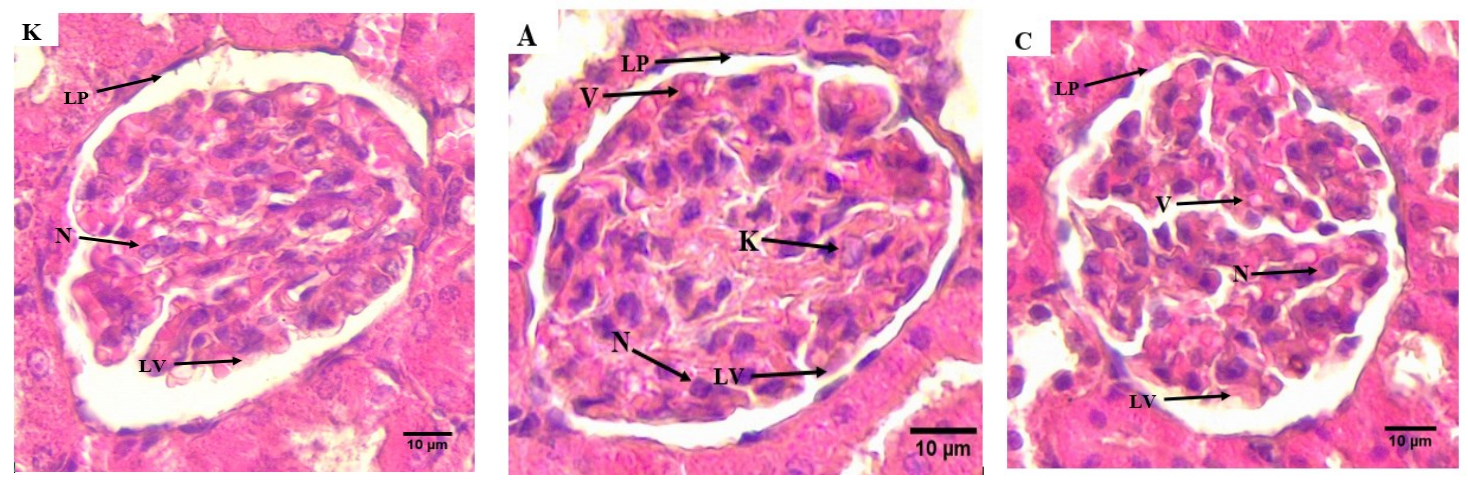

Figure 2. Glomerular microscopic of female rats (Rattus norvegicus, Berkenhout 1769) Wistar Strain with A. maxima and C. vulgaris treatment in subchronic orally toxicity test. C) Control, A) Treated by Arthrospira maxima, C) treated by $C$. vulgaris. Visible parietal lamina (LP), visceral lamina (LV), normal cells $(\mathrm{N})$, karyorrhexis $(\mathrm{K})$ cells, and vacuolization $(\mathrm{V})$.

\section{CONCLUSIONS}

Based on the results, it can be concluded that the microalgae subchronic orally toxicity test Arthrospira maxima and Chlorella vulgaris $2500 \mathrm{mg} / \mathrm{kg}$ of body weight in dose increase blood creatinine and urea levels but are still normal value. There were no damage histological structures of the glomerular kidney of female Wistar rats (Rattus norvegicus Berkenhout, 1769).

\section{ACKNOWLEDGEMENTS}

We would like to thank all those who helped in the completion of this research, our Microalgae group research (Rohmi Salamah, Tika Chandra, Kholidatus Silmi, and Deni Putri).

\section{REFERENCES}

Affan, M-A., Lee, D-W., Al-Harbi, S. M., Kim, H-J., Abdulwassi, N.I., Heo, S-J., Oh, C., Park, HS., Ma, C.W., Lee, H-Y., \& Kang, D-H., 2015, Variation of Spirulina maxima biomass production in different depths of urea-used culture medium, Brarilian Journal of Microbiology 46(4), 991-1000.

Gouveia, L., Veloso, V., Reis, A., Fernandes, H., Novais, J. \& Empis, J, 1995, Evolution of pigment composition in Chlorella vulgaris, Bioresource Technology 57(2), 157- 163.
Kim, S-K., 2015, Handbook of Marine Microalgae: Biotechnology Advances, pp. 1-33, Elsevier, London.

Liu, J., Sun, Z. \& Gerken, H., 2014, Recent Advances in Microalgal Biotechnology, OMICS Group International, Foster City, CA.

Safi, C., Zebib, B., Merah, O., Pontalier, P-Y. \& Vaca-Garcia, C., 2014, Morphology, composition, production, processing, and applications of Chlorella vulgaris, Renewable and Sustainable Energy Reviews 35: 265-278.

Susatyo, P., Rifanda, A.A., Simanjuntak, S.B.I. \& Chasanah, T., 2018, Antioxidant Effect of Chlorella vulgaris on Wistar Rat Kidney Induced by CCl4: A Histopathological Review, Biosaintifika 10(1), 169-175.

Verdiansah, 2016, Pemeriksaan Fungsi Ginjal [Renal Function Tests], Cermin Dunia Kedokteran 43(2), 148-154.

Elzawahry, Z.A., Abass, M.A., El-Haleem, M.R., Hamid, R.I., \& Atteia, H.H., 2016, Spirulina protects against tacrolimus-induced hepatic and renal toxicity in rats: A biochemical and histological study, Journal of Toxicology and Environmental Health Sciences 8(7), 47-55. 